\title{
Author's response to letter from Drs. Vetrano, Devigili, and Nazzi
}

\author{
Michael S. Nirenberg ${ }^{1}$
}

Received: 9 May 2020 / Accepted: 11 May 2020 / Published online: 25 May 2020

(C) Springer-Verlag GmbH Austria, part of Springer Nature 2020

Dear Drs. Vetrano, Devigili, and Nazzi,

Thank you for taking time to express your opinions on my approach to assist with the diagnosis of entrapment of the common peroneal nerve at the fibular neck.

I agree that a larger sample size would be helpful (as stated in my paper), and with such numbers, statistical analysis could be done. I am pleased that you agree with my approach: the critical need to make the correct diagnosis of this nerve compression. We all agree that this diagnosis can be difficult to determine in the presence of a lumbosacral radiculopathy and that electrodiagnostic testing can have limitations. I also concur that EMG is operator-dependent, which, as you state, can result in its failure. Though this may not be "strictly" the case, as Yalinay Dikmen et al.-whom you reference-state in their concluding paragraph, "Pain experienced during EMG procedures may lead to incomplete, unsatisfactory and inconclusive results" [1].

These issues are precisely the reasons I have proposed that an injection of lidocaine into the peroneus longus muscle may help diagnose this nerve entrapment. My paper does not propose this test as a replacement for electrodiagnostic testing, nor should it be interpreted as reducing the important value of electrodiagnostic testing, when performed correctly. My paper states that the lidocaine injection test may "assist" in the diagnosis of common peroneal nerve entrapment, and where there is a positive result, it predicts a good clinical outcome after surgical decompression. I feel that the proposed mechanism of action of the lidocaine test could lead to new, non-surgical treatments for common peroneal nerve entrapment and hope that my paper sparks further study in this area.

\section{Reference}

1. Yalinay Dikmen P, Ilgaz Aydinlar E, Karlikaya G (2013) Expected and experienced pain levels in electromyography. Noro Psikiyatr Ars 50(4):364-367

Publisher's note Springer Nature remains neutral with regard to jurisdictional claims in published maps and institutional affiliations.

This article is part of the Topical Collection on Peripheral Nerves

Michael S. Nirenberg

info@friendlyfootcare.com

1 Friendly Foot Care, PC, 50 W. 94th Place, Crown Point, IN 46307, USA 